\title{
La diversidad del español en Álava: Sistemas pronominales a partir de las encuestas de COSER*
}

\author{
The diversity of Spanish in Álava: \\ Pronominal systems after the surveys of COSER
}

\author{
Bruno Camus Bergareche \\ Universidad de Castilla-La Mancha \\ Sara Gómez Seibane \\ Universidad de La Rioja
}

RESUMEN: Este trabajo describe el uso de los clíticos de objeto directo e indirecto en el habla de distintas zonas de Álava (País Vasco) a partir de los datos del COSER (Fernández-Ordóñez, 2005-), lo que permitirá descubrir varios de los sistemas pronominales descritos para el español septentrional peninsular y su distribución geográfica en el territorio alavés. Los datos obtenidos sirven como argumento a favor de la presencia en Álava de los llamados romance patrimonial y romance importado, descritos en Camus y Gómez (2012).

Palabras clave: sistema pronominal, leísmo, concordancia de materia, omisión de objetos, castellano del País Vasco, romance patrimonial, romance importado.

ABSTRACT: This paper analyses the use of accusative and dative clitics in oral interactions of native Spanish speakers in the Basque Country. Records belong to the COSER corpus (Fernández-Ordóñez, 2005-). The data show some of the pronominal systems described in northern peninsular Spanish and their geographical spread in this area. Specifically, the outcomes reveal the existence in Álava (Basque Country) of the socalled inherited Romance and imported Romance (Camus y Gómez, 2012).

Keywords: pronominal system, leísmo, mass neuter, null objects, Basque Spanish, inherited Romance, imported Romance.

\footnotetext{
* El presente trabajo ha sido financiado con cargo al proyecto de investigación "Español en contacto con otras lenguas: Variación y cambio lingüístico" (FFI2012-31702) del Ministerio de Economía y Competitividad. Agradecemos los comentarios y sugerencias de los revisores anónimos de este trabajo que, sin duda, han contribuido a mejorar la versión final de este texto. Los errores, por supuesto, son solo nuestros.
} 


\section{INTRODUCCIÓN}

En los últimos años, la investigación sobre las características del español en contacto secular con la lengua vasca, tanto en su vertiente histórica como actual, ha experimentado un sensible avance. Muchos de los rasgos peculiares de este contacto fueron fijados en los trabajos ya clásicos de Echaide (1968) y Zárate (1976) a partir de los datos del español hablado por vascohablantes en Orio (Guipúzcoa) y el Txorierri (Vizcaya), respectivamente. Estos rasgos y otros nuevos se describen con precisión en trabajos posteriores. Sin ánimo de ser exhaustivos en las menciones bibliográficas ${ }^{1}$, encontramos progresos en todos los niveles lingüísticos —fonético (Túrrez, 1988; Elordieta, 2003; Iribar e Isasi, 2008), (morfo)sintáctico (Landa y Franco, 1992; Landa, 1993; Fernández Ulloa, 2001; Camus Bergareche, 2011a y 2011b; Gómez Seibane, 2012b; Ramírez Luengo, 2012) y léxico (Etxebarria, 1986; Torres Garoña, 1993; Echeverria Isusquiza, 2012)—, como sintetizan los varios trabajos de conjunto (Urrutia, 1988; Echenique, 1996; Oñederra, 2004).

En este marco, uno de los aspectos que mayor interés ha suscitado son los fenómenos relacionados con el uso de los pronombres átonos de tercera persona. La hipótesis más extendida considera que el contacto linguiístico entre la lengua vasca y el español supuso la reducción del paradigma pronominal a le/s en gran parte de los hablantes, así como dos tendencias, en principio opuestas, como la omisión del pronombre de acusativo en contextos en que su presencia sería obligatoria y el doblado pronominal de objetos directos léxicos. Este uso, conocido como 'sistema vasco' y descrito para gran parte del País Vasco y el norte de Navarra, es uno de los sistemas de organización pronominal detectado en la oralidad por Fernández-Ordóñez (1994 y 1999), cuyo origen parece estar relacionado con el grado de dominio del español ${ }^{2}$, sobre todo en la expresión del género gramatical, categoría flexiva inexistente en la lengua vasca (Echaide, 1968; Echenique, 1986 y 1997; Korkostegi, 1992; Landa, 1993; Urrutia, 1988 y 2006).

\footnotetext{
1 En este sentido, nos remitimos a las referencias bibliográficas recogidas en Gómez y Ramírez (2007), así como en Camus y Gómez (2012: 1-17).

${ }^{2}$ Al parecer, los bilingües de nivel sociocultural bajo y de conocimiento rudimentario del español tienden a omitir la mayoría de los pronombres de acusativo, incluso los referidos a objetos animados (Landa, 1993). En un nivel más avanzado de dominio del español, se alterna la supresión de objeto directo con la extensión de $l e(s)$ al acusativo, único que puede referir tanto a antecedentes masculinos como femeninos (Urrutia, 2006). Esta opción se ve reforzada por la analogía entre le y los pronombres de primera y segunda personas, me y $t e$, sin distinción de género ni caso y con antecedente personal, tal como ocurre con le en más del $90 \%$ de los casos (Fernández-Ordóñez, 1994 y 1999). Finalmente, los hablantes con un grado superior de dominio del español emplean le para referentes personales de objeto directo e indirecto y lo/la con objeto directo de referente inanimado o animado.
} 
Sin embargo, los usos pronominales detectados en el País Vasco no se agotan en el sistema vasco. En efecto, la dialectología actual ha señalado que en el occidente alavés y vizcaíno existe un sistema con leísmo animado y de objeto masculino, cierto laísmo y el empleo de lo para sustantivos contables o de materia femeninos (García González, 1989 y 1999; Fernández-Ordóñez, 1994 y 2001). Es evidente, por tanto, el interés y la oportunidad de continuar con la caracterización de esta zona de la gramática en áreas menos investigadas, como la alavesa.

Por otro lado, el avance en la caracterización del español hablado en la zona vasca ha permitido afinar la percepción sobre la presencia histórica del romance en el espacio que actualmente corresponde al País Vasco. Así, siguiendo el planteamiento de análisis de Saralegui (2011) para Navarra, en el País Vasco, junto al castellano aprendido por vascohablantes nativos —objeto de interés desde los Siglos de Oro y probablemente el que mayor volumen bibliográfico ha generado-, encontramos básicamente dos tipos de romance, uno patrimonial y otro importado (Camus Bergareche, 2011b; Camus y Gómez, 2012: 1-17). El llamado romance patrimonial es el resultado natural del latín hablado en las comarcas del borde occidental y meridional del territorio vasco, básicamente el occidente de Vizcaya y las riberas del Ebro, donde la presencia romana fue más intensa, continua y duradera, como lo prueba, por ejemplo, la relativa abundancia de restos arqueológicos y epigráficos latinos. Romance importado, por su parte, se aplica a la variedad castellana que actuó en el proceso de desplazamiento linguiístico que originó el importante retroceso geográfico de la lengua vasca a lo largo de los siglos XVI, XVII y XVIII, así como el retroceso geográfico y social a partir del siglo XIX. Ambos tipos de romance serán descritos de forma detallada en este trabajo, así como su presencia y manifestación hipotética en los usos pronominales localizados en territorio alavés.

La distinción romance importado / romance patrimonial para el País Vasco coincide, al menos parcialmente, con las ideas defendidas en otros trabajos, como el de Gorrochategui (1999), para el que los posibles focos de latinidad del interior del País Vasco no tuvieron continuidad y se convirtieron en una más de las Romanias perdidas, a excepción del uso del latín como lengua de la Iglesia en la Alta Edad Media. En el marco de esta hipótesis se inserta el concepto de romance importado propuesto más arriba. Sin embargo, esta misma noción discrepa de la propuesta de Echenique (1986: 160 y 1997: 163), quien sostiene la hipótesis de la continuidad entre la lengua de los núcleos latinos antiguos y el castellano actual del interior del País Vasco. Por su parte, en lo que se refiere al concepto de romance patrimonial en el ámbito alavés, conviene recordar la caracterización de los especialistas en la tradición escrita romance, como Santiago (1977: 244), quien precisó que la lengua utilizada en la documentación medieval era un castellano "arcaizante en alguna de sus 
manifestaciones y particularmente teñido de dialectalismos de origen oriental (navarro-aragonés) y riojano".

El objetivo de este trabajo es, por tanto, doble. Por un lado, se trata de completar la caracterización de los usos pronominales de Álava, territorio especialmente desatendido por la investigación lingüística del área vasca, para lo cual se han utilizado los datos proporcionados por las encuestas del proyecto COSER, el Corpus oral y sonoro del español rural (Fernández-Ordóñez, 2005-). Por otro lado, se presentan argumentos lingüísticos en favor de una consideración del español de esta área septentrional como una realidad compleja, formada por la superposición de distintos estratos lingüísticos de historia y naturaleza diferentes, tal como han defendido, entre otros, González Ollé (1991: 61-62), Saralegui (2011: 79-80) o Echevarria Isusquiza (2012: 112-116). Con respecto a este último asunto, no se nos oculta la dificultad de la tarea, sobre la que volveremos en el futuro con otros argumentos lingüísticos que completen esta primera caracterización basada en los usos pronominales átonos. En todo caso, es muy oportuna la reciente reflexión de Echenique (2013a), que reproducimos a continuación:

En cualquier caso, ni siquiera hoy resulta fácil separar con nitidez fronteras dialectales específicas del antiguo espacio castellano respecto a sus aledaños astur-leonés, navarro o aragonés y, de hecho, la crítica textual aplicada a las primeras manifestaciones literarias romances dista mucho de encontrar interpretaciones que satisfagan al común de los estudiosos (Echenique, 2013a: 28).

Con ese propósito este trabajo se organiza de la siguiente manera. En primer lugar, en el apartado 1 se presentan los sistemas pronominales detectados en el norte del dominio español peninsular, de manera que sirva de referencia para situar adecuadamente los datos relativos al español de Álava. El apartado 2 ofrecerá una descripción pormenorizada de los datos relativos al uso de los clíticos pronominales que las encuestas del proyecto COSER muestran para las localidades consideradas en Álava. El apartado 3 se dedicará a la discusión de estos datos en el marco más amplio del debate en torno a las distintas variedades de romance presentes en el territorio vasco actual. Serán fundamentales para esta recapitulación las consideraciones contenidas en los trabajos de Saralegui y Lesaca (2002), Saralegui (2006, 2011), así como su reelaboración para el castellano del País Vasco en Camus Bergareche (2011b) y Camus y Gómez (2012).

\section{SISTEMAS PRONOMINALES EN EL ESPAÑOL PENINSULAR SEPTENTRIONAL}

Como es sabido, una de las variables lingüísticas relevantes para definir distintas modalidades dialectales en el dominio hispanohablante, especialmente 
en España, es la selección de las formas pronominales que permiten recuperar los distintos complementos de un verbo. Frente a la presencia del sistema pronominal distinguidor del caso en buena parte del español peninsular, el territorio septentrional — por tanto, también el País Vasco-, es por excelencia la zona de variación en los sistemas pronominales de acusativo y dativo. De acuerdo con las descripciones de Fernández-Ordóñez (1994, 1999 y 2001), la variación podría sintetizarse en la Tabla 1, donde se contraponen los distintos sistemas descritos en el norte peninsular y los fenómenos de variación atestiguados en esa zona. Tales fenómenos pueden desencadenar variaciones en el caso (leísmo, laísmo y loísmo), pueden superponer el rasgo de continuidad sobre el de género en la concordancia de los sustantivos (concordancia de materia) o pueden omitir el pronombre de acusativo en referencia a objetos directos definidos y específicos (objetos nulos). La organización de estos fenómenos, por su parte, configura los distintos sistemas pronominales septentrionales, como son el astur-cántabro, el vasco y el referencial, así como los sistemas de transición a partir de la presión de estos sistemas sobre el sistema distinguidor del caso, heredado del latín.

\begin{tabular}{|c|c|c|c|c|c|c|c|c|c|}
\hline & \multicolumn{4}{|c|}{ Leísmo } & \multirow{3}{*}{$\begin{array}{c}\text { Concordancia } \\
\text { de materia }\end{array}$} & \multirow{3}{*}{ Laísmo } & \multirow{3}{*}{ Loísmo } & \multirow{3}{*}{$\begin{array}{c}\text { Objeto } \\
\text { nulo }\end{array}$} \\
\hline & & \multicolumn{2}{|c|}{ masculino } & \multicolumn{2}{|c|}{ femenino } & & & & \\
\hline & & $\begin{array}{c}+ \\
\text { anim. }\end{array}$ & $\begin{array}{c}- \\
\text { anim. }\end{array}$ & $\begin{array}{c}+ \\
\text { anim. }\end{array}$ & $\begin{array}{c}- \\
\text { anim. }\end{array}$ & & & & \\
\hline \multirow{3}{*}{$\begin{array}{l}\text { Astur- } \\
\text { cántabro }\end{array}$} & Asturiano & & & & & + & & & \\
\hline & Cántabro & & - & & & + & * & * & \\
\hline & Transición & & + & & & $\sqrt{ }$ & * & & \\
\hline \multicolumn{2}{|c|}{ Vasco } & + & & + & & & & & $\sqrt{ }$ \\
\hline \multicolumn{2}{|c|}{ Referencial } & \multirow{2}{*}{\multicolumn{2}{|c|}{$\frac{+}{\sim}$}} & & & + & + & + & \\
\hline \multicolumn{2}{|c|}{ Distinguidor } & & & & & & & & \\
\hline
\end{tabular}

+ muy frecuente

$\sqrt{\text { opcional }}$

$\sim$ posible, relativamente frecuente

* marginal

TABLA 1.-Rasgos de los sistemas pronominales del español peninsular septentrional.

En primer lugar, el sistema astur-cántabro se extiende por gran parte del norte peninsular, con ciertas peculiaridades distintivas en función de la zona en la que se encuentre. De esta manera, el sistema asturiano, presente en el centrooriente asturiano y en parte de Cantabria, superpone en el acusativo los rasgos semánticos continuos de los referentes sobre su género gramatical (concordan- 
cia de materia), mientras que para los discontinuos atiende a las distinciones de género y caso. El sistema cántabro, por su parte, comparte las características del asturiano, salvo una importante diferencia: el uso de le como única forma para acusativo y dativo masculino con referentes discontinuos. Además, en las comarcas rurales y montañosas del centro-oriente de Cantabria se observan algunos cambios tendentes a la indistinción de los casos, por lo que son relativamente comunes el laísmo, el loísmo y el leísmo plural. Junto a estos dos sistemas, y como consecuencia de la presión de los sistemas astur-cántabro y vasco, surge el sistema de transición nororiental documentado en la comarca vizcaína de Las Encartaciones, parte de Álava y esquina nororiental de Burgos. En este sistema, el leísmo afecta a la mayoría de referentes masculinos discontinuos, mientras que los referentes continuos, masculinos y femeninos, tienden a pronominalizarse con lo. Los pronombres de dativo, por su parte, se mantienen con regularidad, salvo algún caso de laísmo en singular.

En segundo lugar, el sistema vasco domina gran parte del País Vasco y el norte de Navarra, tanto en hablantes bilingües de vasco y español como en monolingües de español. En esta zona, el leísmo se extiende a todos los referentes animados, con independencia de su género, mientras que el clítico de los objetos directos definidos y específicos, sobre todo inanimados, pero también los animados, puede omitirse.

En tercer lugar, desde la mitad noroccidental de Castilla hasta La Mancha, se despliega el sistema referencial, basado en los rasgos semánticos del referente. En efecto, este sistema anula el caso como parámetro de selección pronominal y atiende a ciertos rasgos del sustantivo. En primer lugar, distingue formalmente nombres continuos y discontinuos y entre estos, a su vez, presta atención al género y al número. La indistinción del caso es prácticamente general en singular y plural, si bien en plural con discontinuos masculinos varía en función de las zonas. Asimismo, del contacto entre el sistema referencial y el distinguidor surgen dos variantes transicionales, que reorganizan parcialmente los parámetros del sistema referencial. Se trata del sistema de transición occidental en la esquina suroriental de León, y el suroriental en el borde occidental de Guadalajara y en los bordes orientales de Toledo y Ciudad Real.

Finalmente, en La Rioja, mitad sur de Navarra y Aragón encontramos el sistema descrito como distinguidor, basado en el parámetro de caso, sin la marcación de la continuidad y con la distinción genérica restringida a la función de objeto directo (Fernández-Ordóñez, 1994: 113 nota 79). La distribución geográfica de la variación en los sistemas pronominales que acabamos de describir puede trazarse como se recoge en el Mapa $1^{3}$.

\footnotetext{
${ }^{3}$ Es obligado agradecer la imprescindible ayuda de Enrique Garrido para la elaboración de este y los siguientes mapas.
} 


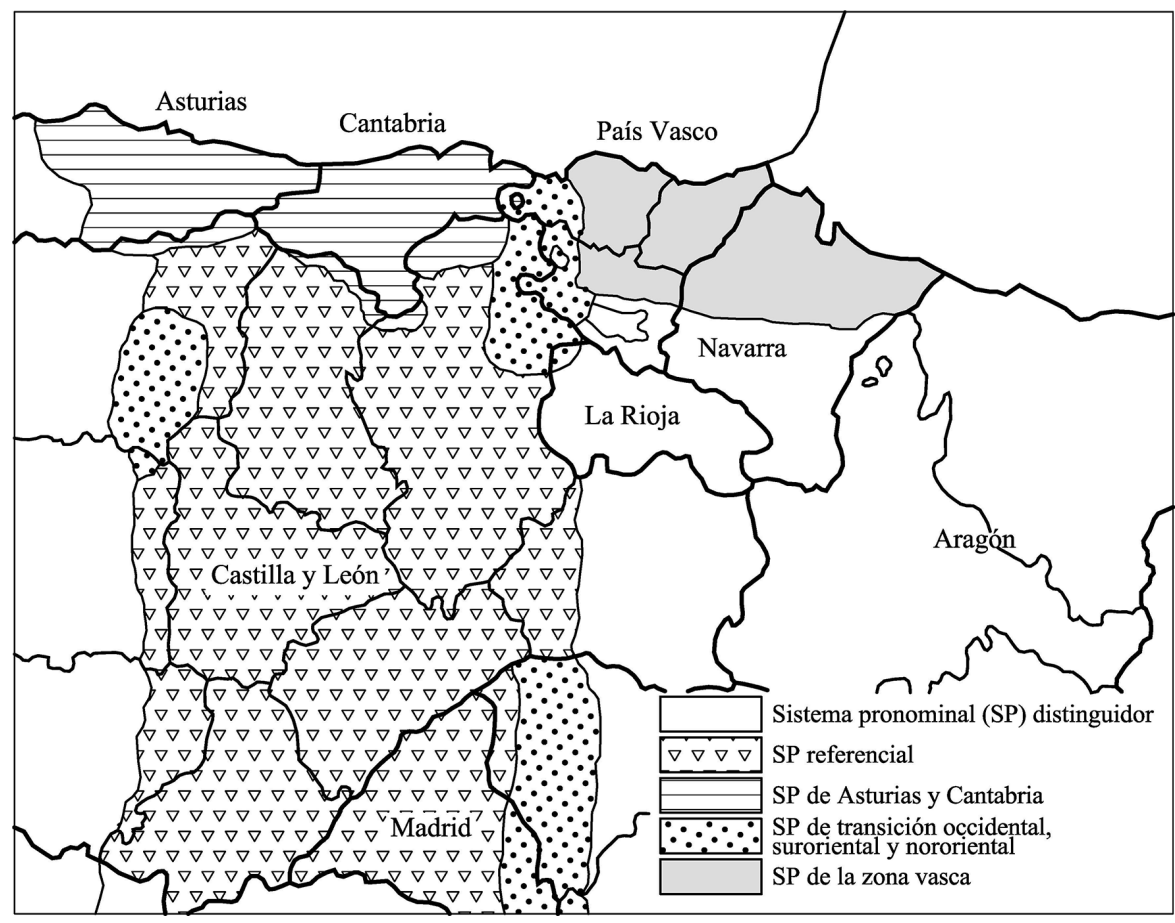

MAPA 1.-Sistemas pronominales en el norte de España (adaptado de Gómez Seibane, 2012a: 30)4

Recapitulando entonces lo expuesto hasta el momento, nos interesa recalcar especialmente cómo la variación en los sistemas pronominales del norte peninsular queda organizada en torno a dos rasgos: a) la existencia o no de marcación distintiva para sustantivos continuos o de materia (concordancia de materia) y b) el mantenimiento o no del parámetro de caso como criterio decisivo en la selección pronominal. Son dos características a las que recurriremos en el apartado siguiente para describir los usos pronominales alaveses.

\section{Sistemas PRONOMINALES EN ÁlaVA A PARTIR DEL COSER}

Como se verá a lo largo de este apartado, el análisis detallado de los materiales orales contemporáneos que proporciona un corpus como el COSER resul-

${ }^{4}$ Reproducimos en este trabajo la leyenda que aparece en Gómez Seibane (2012a: 30), en la que el llamado "sistema pronominal vasco" se extiende desde el centro de Vizcaya al norte de Navarra pasando por Guipúzcoa. En el citado libro, la leyenda del mapa denomina "vasco" a este espacio en el sentido de 'vascohablante' o con importante uso de la lengua vasca junto al español. 
ta un procedimiento ideal para confirmar la hipótesis de que Álava, pese a ser un territorio pequeño, resulta un espacio lingüístico complejo de gran interés para el continuo septentrional.

\subsection{Los puntos encuestados y las encuestas}

Los materiales del proyecto COSER que se describirán en las páginas siguientes corresponden a la totalidad de los puntos encuestados en Álava, es decir, los que recogemos en la Tabla 2 (Fernández-Ordóñez, 2005-: Mapas). Hemos tenido acceso a la grabación y transcripción de todas las encuestas excepto en el caso de Elciego, punto para el que tenemos únicamente las grabaciones ${ }^{5}$.

\begin{tabular}{|l|l|}
\hline \multicolumn{2}{|c|}{ Localidades de la encuesta COSER en Álava } \\
\hline 101 Barriobusto & 102 Berganzo \\
\hline 103 El Burgo (sic) & 104 Elciego \\
\hline 105 Guinea & 106 Leza \\
\hline 107 Luzuriaga & 108 Maestu \\
\hline 109 Menagaray & 110 Murúa (sic) \\
\hline 111 Salinas de Añana & 112 Turiso \\
\hline
\end{tabular}

TABla 2.-El COSER en Álava.

Las encuestas corresponden, por tanto, a una localidad de la cuadrilla de Ayala (Menagarai), una de Zuia (Murua), cuatro de la cuadrilla sudoccidental de Añana (Salinas de Añana, Guinea, Turiso y Berganzo), dos de la de Salvatierra (Luzuriaga y Elburgo), una de la cuadrilla de Campezo-Montaña alavesa (Maeztu) y tres de la de Laguardia-Rioja alavesa (Leza, Elciego y Barriobusto $)^{7}$. Esto es, una muestra de doce lugares en total y, por tanto, razonablemente representativa en términos geográficos, como recoge el Mapa 2.

\footnotetext{
${ }^{5}$ Queremos expresar nuestro agradecimiento a Carlota de Benito y a Inés Fernández-Ordóñez por permitirnos el acceso a las encuestas alavesas del COSER y los materiales correspondientes, buena parte de los cuales no están todavía disponibles en red. Sin su excelente disposición y amabilidad este trabajo no hubiera sido posible.

${ }^{6}$ Para el COSER se usan los topónimos tradicionales en español y así los reproducimos nosotros en esta tabla. Sin embargo, es preciso señalar que en el español de la zona se dice Murua, con acento en la primera "u" y sin hiato. Asimismo, la denominación oficial en español es Elburgo y no El Burgo. En el texto del trabajo, por el contrario, usaremos siempre la denominación oficial del lugar, que en algún caso, como el de Menagarai o Maeztu (y Gordexola en Vizcaya), corresponde al nombre en vasco y difiere del tradicional en español.

${ }^{7}$ Cuadrilla es la denominación que recibían cada una de las partes en que se dividía Álava desde finales de la Edad Media. La actual división comarcal ha recuperado esta denominación, de
} 


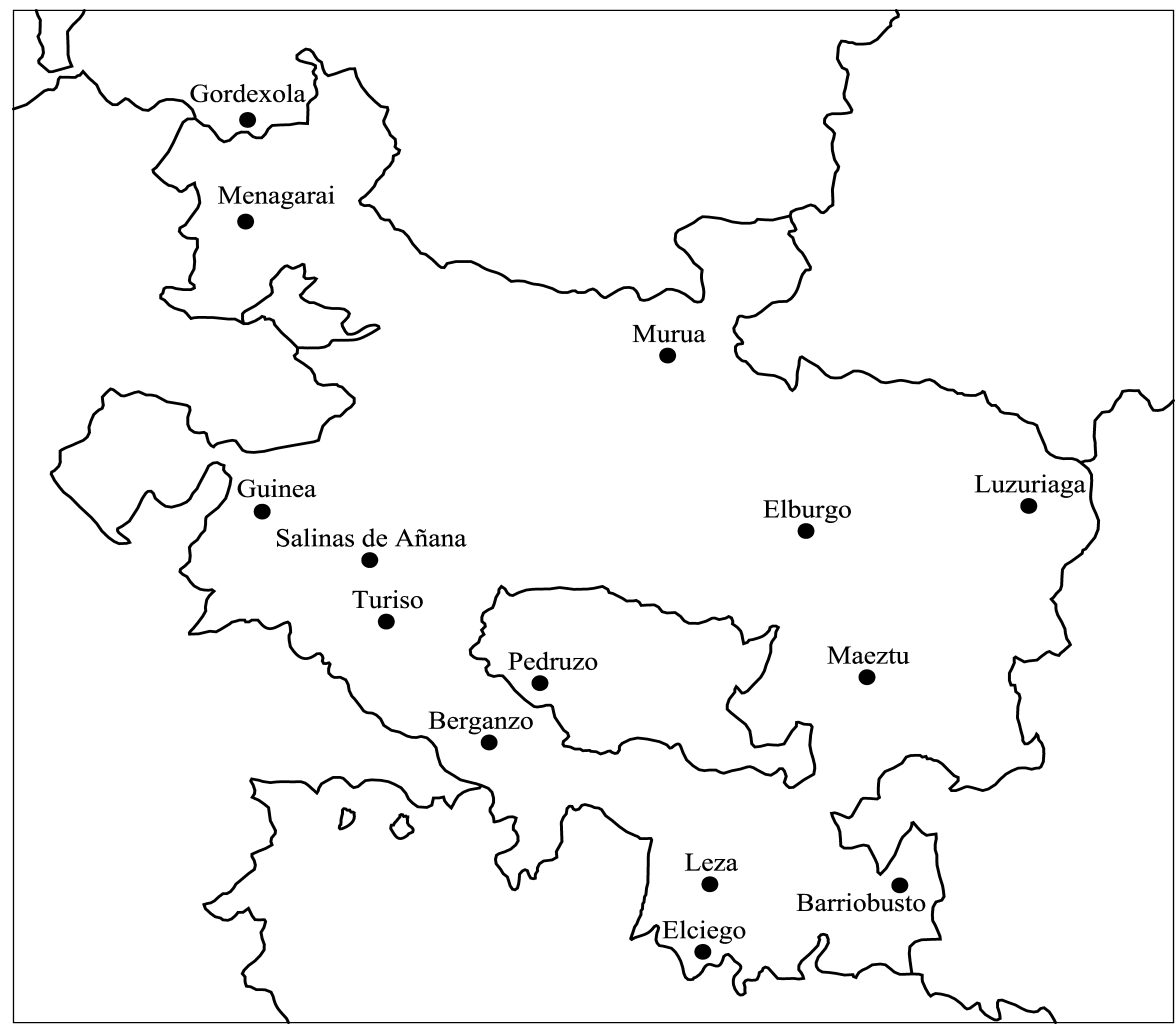

MAPA 2.-Localidades alavesas encuestadas para el COSER.

Como se ve, aparecen en el mapa otras dos localidades encuestadas en el proyecto COSER que no corresponden administrativamente al territorio de Álava. Son, en primer lugar, Gordexola en Vizcaya, que hemos incluido con el fin de poder poner de manifiesto las eventuales relaciones entre las Encartaciones vizcaínas, a las que pertenece la localidad citada, y el contiguo valle alavés de Ayala. En segundo lugar, contaremos con los datos de la localidad de Pedruzo, en el Condado de Treviño, que pertenece administrativamente a la provincia de Burgos, pero está enclavado en el corazón de Álava. De ahí que sus datos resulten absolutamente pertinentes para completar el cuadro de las hablas de esta área geográfica. Las encuestas correspondientes a estos dos lugares están ambas disponibles en red en la página web del proyecto; son respectivamente los puntos Vi 4506 Gordejuela ${ }^{8}$ y Bu 0934 Pedruzo.

modo que hoy existen siete cuadrillas: Ayala, Añana, Zuia, Vitoria, Salvatierra, Laguardia-Rioja alavesa y Campezo-Montaña alavesa. Son estas subdivisiones las que seguimos en este trabajo.

${ }^{8}$ Véase la nota 3 más arriba. 
Las encuestas analizadas se realizaron en diversas campañas (1992, 1993, 1997 y 2000), normalmente por dos encuestadores que formaban parte de equipos de estudiantes en prácticas de la UAM dirigidos siempre por Inés Fernández-Ordóñez. Se trata de entrevistas semidirigidas con personas de alrededor de setenta años con una duración que puede variar desde media hora hasta algo más de una hora ${ }^{9}$.

\subsection{La distribución geográfica de los sistemas pronominales}

Una vez revisadas las encuestas y organizados los datos, se descubren en la provincia de Álava distintos usos pronominales, que en líneas generales coinciden, como ya indicamos más arriba, con algunos de los descritos en el norte peninsular. A continuación se presenta una descripción, ordenada por zonas geográficas, de los diferentes sistemas atestiguados (\$2.2.1-2.2.4); asimismo, al final de esta descripción se ofrece un cuadro que sintetiza los rasgos principales de estos sistemas en cada punto analizado (\$2.2.5) y un mapa que traza la continuidad de los distintos sistemas descubiertos (\$2.2.6). Debemos advertir, con todo, que, del mismo modo que parece obligado reconocer la existencia de áreas lingüísticas bien diferenciadas, es cierto también que los límites entre estas están lejos de ser absolutos y, como se verá, el habla de algunas localidades muestra cierta mezcla de rasgos y características menos nítidas.

2.2.1. El occidente (Ayala y Añana). El sistema pronominal utilizado en toda la franja occidental de Álava en contacto con Burgos — desde el norte (Menagarai) hasta el sur (Berganzo), pasando por Guinea, Turiso y Salinas de Añana- coincide básicamente con el de Las Encartaciones vizcaínas. Es el denominado sistema de transición nororiental (Fernández-Ordóñez, 2001: 405), muy presente en municipios próximos a esta zona alavesa analizada, como Gordexola (Vizcaya). Este sistema, entre el referencial y el distinguidor y fuertemente influido por el sistema vasco, se caracteriza por la extensión del leísmo a la mayor parte de referentes masculinos discontinuos, tanto singulares como plurales, mientras que los referentes continuos tienden a pronominalizarse en lo. Los pronombres de dativo, por su parte, se mantienen con regularidad, salvo algún caso de laísmo.

Así, especialmente en Guinea y Turiso se observa una expresión muy sistemática de la concordancia continua referida a entidades femeninas (leña, manteca, paja) mediante lo o bien con ello si hay referentes masculinos (queso) (1). Si bien la continuidad gobierna la concordancia en toda la zona señalada, en ocasiones estos sustantivos continuos femeninos también se pronominalizan con la.

\footnotetext{
${ }^{9}$ Véanse para los detalles los apartados de Descripción y Metodología en la página web del Proyecto COSER (Fernández-Ordóñez, 2005-: Presentación).
} 
(1) a. [masa] Sobarlo bien, ponerlo en una tabla. [leche] Dejarlo que se cuaje, luego irlo pasando que despida el suero. [manteca] La manteca no, porque lo echas pa las morcillas. (Menagarai).

b. [lana] Venían, lo compraban, y lo llevaban en sucio todo, recién esquilao, ellos lo arreglarían para luego, para hilarlo. [tierra] Pues maquinarlo, maquinarlo por abajo. [parva] En una hora lo tendíamos [...] luego abeldarlo, y a recogerlo. (Turiso).

c. Amontonao la leña, y tápalo [...] Lo amontonabas, lo tapabas. [paja] Pues echáselo a los bichos, a las vacas. Se cogía antes poco, ahora lo cogen las cosechadoras, pero pa aquí pa casa. [queso] Había que tener cuidao de ello también. (Guinea).

d. La paja cuando se segaba traelo con un carro, traelo con un carro, pero después para llevarlo a Vizcaya o a Bilbao con fardos de a mano. (Berganzo).

e. [mies] Las cosechadoras lo cogen. [leche] Luego íbamos los vecinos a comprárselo [...] lo llevan a la centrales lecheras que llaman. (Salinas de Añana).

Asimismo, en esta zona es muy frecuente el leísmo humano masculino (2). Ahora bien, para la referencia a entidades animadas, si bien el leísmo resulta la opción preferida, le/s alterna en ocasiones con $l o / s$ (3).

(2) a. [estudiantes] Les lleva el autobús y les trae al mediodía a comer. [difunto] Al día siguiente ya le enterraban [...] tenías que amortajarle. [hijos] A algunos no les bautizan, yo les bautizaba enseguida. (Menagarai).

b. [niños] Amamantarles solían todos. (Guinea).

c. [conejo] Si te hacía falta uno pues le matabas. [zorro] Esperarle a ver si venía. [segadores] tú les tenías que mantener. (Berganzo).

(3) a. Pues matarlo, matar el cerdo [...] Aquí no solía nadie de casa matarle $[. .$.$] no creas que todos aprendían a matarle, y además tres o cuatro$ para tenerle también además. (Turiso).

b. [cerdo] Le matan, luego le queman, le queman con halechos [...] Como no lo puedes comer pues no lo matas. (Menagarai).

En Turiso y Salinas de Añana, por su parte, la alternancia de $l e / s$ y $l o / s$ ocurre también con referentes inanimados masculinos (muñeco, chorizo) y esporádicamente, incluso con continuos (magro).

(4) a. [chorizo] Les teníamos dos o tres días en adobo, [...] luego pues a hacerlos y colgarlos en la cocina pa que se secaran [...] Los metíamos en terrazas con manteca. El magro pues picarle, y luego pues echarle la sal que había necesario, y el pimentón, y los ajos. (Turiso).

b. [muñeco] Ya lo colocan en el árbol [...] Le ponen con una bolsita con las monedas, y le ponen en el árbol. [chorizo] El otro le guardaban, si no le guardaban metían los dos. (Salinas de Añana). 
Entre los fenómenos de detección más ocasional se encuentra la omisión de objetos definidos (5), así como varios testimonios de loísmo (6) referidos a entidades de materia femenina (morcilla), masculina (queso) y en construcciones con verbos de sentido general acompañados de objeto, como dar la vuelta (7), reinterpretados analógicamente como transitivos (voltear).

(5) a. Hay muchas formas de hacerlo [el bizcocho] yo siempre $\varnothing$ he comprao [...] no les $\varnothing$ he hecho ya porque no merece la pena. Eso ya te $\varnothing$ llevan [el colchón]. (Menagarai).

b. [los chorizos] Unos 15 días o 20 había que tener $\emptyset$ (Turiso).

(6) a. [la morcilla] Yo al menos no lo echo mas que pimienta, la pimienta es la única especia que se le echa. (Menagarai).

b. [queso] Lo ties que poner un trapo porque si no no cuela. (Guinea).

(7) [cerdo] Luego lo dan la vuelta, y le vuelven a churrumar (Salinas de Añana).

Este sistema pronominal de transición alcanza Pedruzo (Treviño, Burgos), aunque aparece muy debilitado. En efecto, en esta localidad se detecta un sistema básicamente distinguidor, con varios testimonios de leísmo en referencia a animados (8) y otro de laísmo (9), así como casos esporádicos de concordancia neutra (10), especialmente a distancia, y algún que otro ejemplo de objeto nulo (11).

(8) [cerdos] Hay que agarrarles bien. [cerdo] Tú con el gancho le, le coges de así. Hay que tenerle bien de las patas pa[ra] que no se escape.

(9) No la dejes que se ponga encima.

(10) Se echa cebolla, esto pimienta, y la sal, bueno, la sal se, se echa en el agua... bueno, pero es igual, hay quien lo echa también en el esto, en el, en el esto, en la sangre. Pues eso, se recogía la parga y hacíamos pues eso, lo que dice la Justi, con un, se ponía un montón, y cuando salía el norte pues lo aventaban.

(11) Avisábamos a los del pueblo para que nos ayudasen a tenerlo, porque hay que tener $\emptyset$ entre tres o cuatro.

2.2.2. El norte y el noreste. En el norte y noreste de Álava, en contacto con territorios vizcaínos y guipuzcoanos, las localidades de Murua y Luzuriaga muestran una fuerte tendencia al leísmo y a la omisión de objetos directos definidos, dos de las características determinantes del sistema pronominal de tipo vasco (Fernández-Ordóñez, 1999: 1350). De acuerdo con esta descripción y según se ha observado en las encuestas de COSER, el leísmo es general con entidades humanas y animadas en masculino (12). En Luzuriaga, además, este leísmo es extensivo a entidades humanas femeninas (13).

(12) a. [marido] Si luego te decía algo pues le podías algo regañar como dice ese o no regañar le, pero bueno. [marido] $L e$ hemos tenido en casa y no le hemos llevao a Vitoria nada. [extranjeros] Qué les dejen. [lecheros] Si le echan agua les ven. [yerno] Le han retirao con cincuenta y ocho años. (Murua) 
b. [los niños] Les metían en una media fanega y ya estaban seis horas, ahora cada segundo a mirar le. Pues que les trataban mal al forastero que venía. Les casaban a los novios. (Luzuriaga).

(13) [hija] Resulta que la madre esperándole. [chicas] Iban a acompañarle. (Luzuriaga).

Por añadidura, los usos leístas pueden ampliar su referencia a entidades inanimadas masculinas y femeninas (14), algunas de las cuales son continuas o de masa, como cuajada, masa, magro o tocino. Cabe destacar, en este punto, que no se ha detectado ningún testimonio de concordancia neutra.

(14) a. Vitoria en cualquier sitio, y ves una caja o lo que sea y igual tiene, dices pues tiene dinero, no le tocas. [las tortas] Pues meter $l e$ al horno. [chorizo] Había que probar le. Hasta que les vas comiendo. [cuajada] le cuajan, le, en un trapo, le, le (escorren=escurren), el domingo les vi cómo hacían, pero de poco. ¡Joé!, la miel pues vender le, ¿no habéis comido miel o qué? [horno] La gente le tiró. El horno había que limpiar le. (Luzuriaga).

b. Echábamos a la mañana la masa le dejábamos tanto tiempo, después hacíamos los panes y le volvíamos a dejar otro tiempo pa que se levante. Todo con el cuero, con el cuero que tiene el cerdo y el magro sin quitarle. [tocino] Quemar le bien. (Murua)

El segundo fenómeno ampliamente registrado, sobre todo en Luzuriaga, es la omisión de objetos referidos a entidades definidas y específicas, que en el español normativo exigirían la presencia del pronombre de acusativo (15). En general, los testimonios hallados corroboran algunas de las características sintácticas, semánticas y pragmáticas del fenómeno: se trata de entidades inanimadas, en algunos casos tematizadas o desplazadas a la izquierda del verbo (16) y altamente topicales, esto es, constituyen el tema acerca del cual versa el resto de la oración; resultan, además, fácilmente recuperables y suelen mencionarse en el mismo turno de palabra (Gómez Seibane, 2012b: 207-209). En contraste con la relativa frecuencia con que se manifiesta esta omisión de objetos, usos como el laísmo (17) escasean y solo se registran en un ejemplo de Luzuriaga.

(15) La leche que te sobraba pues $\emptyset$ vendías y la que no pues... tomabas en casa. Los huevos y... la madre $\mathrm{d}[\mathrm{e}]$ ese a Vitoria $\emptyset$ llevaba (Luzuriaga).

(16) a. Mira esos chorizos que tenemos ahora son así, y ahora resulta que $\varnothing$ ponemos con tortilla. Y de ahí sale el queso. El domingo les veía cómo $\emptyset$ hacían. (Luzuriaga).

b. [las alubias] Pues sí, dicen que $\emptyset$ ponen bien. En el Grande dicen que $\varnothing$ ponen bastante bien, no sé. (Murua)

(17) Pues ahora mira, esa finca la han labra[d]o, y la han echado abono. (Luzuriaga).

2.2.3. El centro-este. En el centro del territorio alavés, correspondiente a la llamada Llanada (cuadrillas de Salvatierra y Vitoria), y la cuadrilla de Campezo- 
Montaña alavesa en el este, encontramos un área que resulta ser en parte la continuación de los rasgos descritos para el norte (\$2.2.2) en lo relativo al funcionamiento de los pronombres. Así, se detecta la preferencia por usos leístas, cierta tendencia a la omisión de objetos y la ausencia de concordancia de materia. No obstante, la frecuencia de manifestación tanto del leísmo como de los objetos nulos es menor en comparación con la observada en el norte. De acuerdo con la revisión de los datos del COSER, se pronominalizan en le/s los animados masculinos (18), y en varios casos, algunos femeninos (19).

(18) a. Y ahora los chiquillos con las profesoras, yo les veía. ¿No le conocéis a Suso? [hijo] Todo el mundo le quiere en el pueblo. (Maeztu).

b. Yo los animales localizarles lo tienen muy fácil. Si tenías animales tenías que ir igual a ordeñarles. (Elburgo).

(19) a. Atarle a la yegua allá pa que coma yerba. (Elburgo).

b. Le pillaron a mi madre y desde entonces no tuvo cosa buena. (Maeztu).

La omisión de objetos, por su parte, es también significativa con referentes inanimados (20), si bien resulta menos habitual que en Luzuriaga.

(20) a. Que lo antiguo toavía nos gusta mucho, $\varnothing$ apreciamos mucho. La cazalla es una cosa parecida al orujo, pero es diferente, también $\varnothing$ sacan de la uva, vamos. (Elburgo).

b. [la edad] No $\varnothing$ aparento no. (Maeztu).

Otros fenómenos contrarios al sistema de caso, como el loísmo y el laísmo, se manifiestan muy ocasionalmente (21). A veces se producen en contextos que facilitan su aparición, como en predicados formados por un verbo de sentido general cuyo significado se concreta con un objeto, como tener miedo o dar fuego (21b). En estos contextos, el hablante puede interpretar el predicado como una única forma, con lo que la variación en el caso puede responder a la analogía por su equivalencia con el correlato semántico transitivo, temer o quemar.

(21) a. [a mi madre] La reventaron el bazo. (Maeztu).

b. Se la daba fuego [planta]. Yo al calor lo tengo mucho miedo. (Elburgo).

2.2.4. La Rioja alavesa. En esta última zona se observan algunas diferencias entre los tres puntos analizados, Barriobusto, Elciego y Leza. Los dos primeros muestran una relativa tendencia al leísmo masculino animado, y ocasionalmente inanimado (22), sin presencia de leísmo femenino, neutro de materia ni omisiones de objeto. Se trata, por tanto, de un sistema básicamente etimológico, continuación muy probablemente del sistema descrito hacia el sur para gran parte del área riojana y del sur de Navarra (Fernández-Ordóñez, 1994).

(22) a. Le cogían... al cerdo. Lo... tumbaban, le agarraban uno de cada pata o... y el otro con el gancho le sujetaba. Y a los críos, atenderles. Mira que...le lleva el hombre del saco. [vino] Ese le cogían y lo...y lo echaban a la cuba y ya...pues pa vinagre. Logroño, eh-eh un pueblo cerca de Lardero, no sé si le conocen. (Barriobusto). 
b. [pueblo] Lo quiero con locura [...] por eso le pusieron Elciego, porque había un ciego que regentaba la posada (Elciego).

En Leza, por su parte, se documenta con más frecuencia el leísmo referido a animados, sobre todo masculinos (23), pero también femeninos, tanto animados (24) como inanimados (25).

(23) [cerdo] Están cuatro pa[ra] sujetarle [...] entonces el matarife le está sujetando. El matarife le engancha al cerdo, tira así, le engancha al cerdo, es que no le puedo descolgar. [conejo] Entonces luego ya le sangras. Ahí tengo pa[ra] poner medio jabalí, y no sé cuando le pondré.

(24) [gallinas] Les desplumas un poco, les sujetas bien así, le cortas ahí, retiras la sangre en el fregadero o donde sea, y nada, luego pelarlas.

(25) [barbuda] Si le atan con gracia a la cepa.

Asimismo, el laísmo (26) resulta más frecuente que en otras zonas analizadas y la omisión de objetos directos inanimados definidos, sin ser abundante, sí se atestigua en varias ocasiones (27), especialmente en contextos con doble pronominalización y con objetos tematizados a la izquierda. Esta cercanía de los testimonios de Leza a lo encontrado en lugares como Murua o Luzuriaga puede no ser ajena al hecho de que, como da a entender en la misma entrevista, la informante ha pasado parte de su vida en Guipúzcoa, en ArrasateMondragón, donde tiene familiares que, además, la visitan a menudo.

(26) A pesar de que la carne en echándola la sal, ya aguanta. [tabla] Se te cae lo que la pones. [tablas] Y las pones el peso. Unas pezoneras así largas, las metes a la vaca.

(27) Porque la leche materna es muy buena darles $\emptyset$. Échale un chorretón de anís a las tripas cuando $\varnothing$ tengas limpias. Nada, entonces se cuelgan aquí, los chorizos $\varnothing$ colgamos por estas cuerdas que se les deja.

2.2.5. Síntesis de los rasgos de los sistemas pronominales. De acuerdo con la descripción presentada en los apartados anteriores, en la Tabla 3 se resumen los rasgos fundamentales que caracterizan los sistemas de cada uno de los puntos analizados. Estos rasgos responden a los fenómenos de variación con respecto al parámetro de caso, como son el leísmo, el laísmo y el loísmo, a la distinción del rasgo de continuidad del sustantivo (concordancia de materia) y, finalmente, a la posibilidad de elisión de los pronombres átonos referidos a objetos directos definidos y específicos. Como puede comprobarse, los puntos de encuesta se han reunido de acuerdo con la coincidencia de rasgos y su distribución en la configuración de distintos sistemas pronominales ${ }^{10}$.

${ }^{10}$ Hay que advertir, además, que en la Tabla 3 se han incluido los dos puntos no alaveses a los que aludimos más arriba: Gordexola en Vizcaya y la localidad treviñesa de Pedruzo, cuya presencia se justifica, como dijimos, en la explicación de la continuidad del sistema pronominal de transición nororiental. 


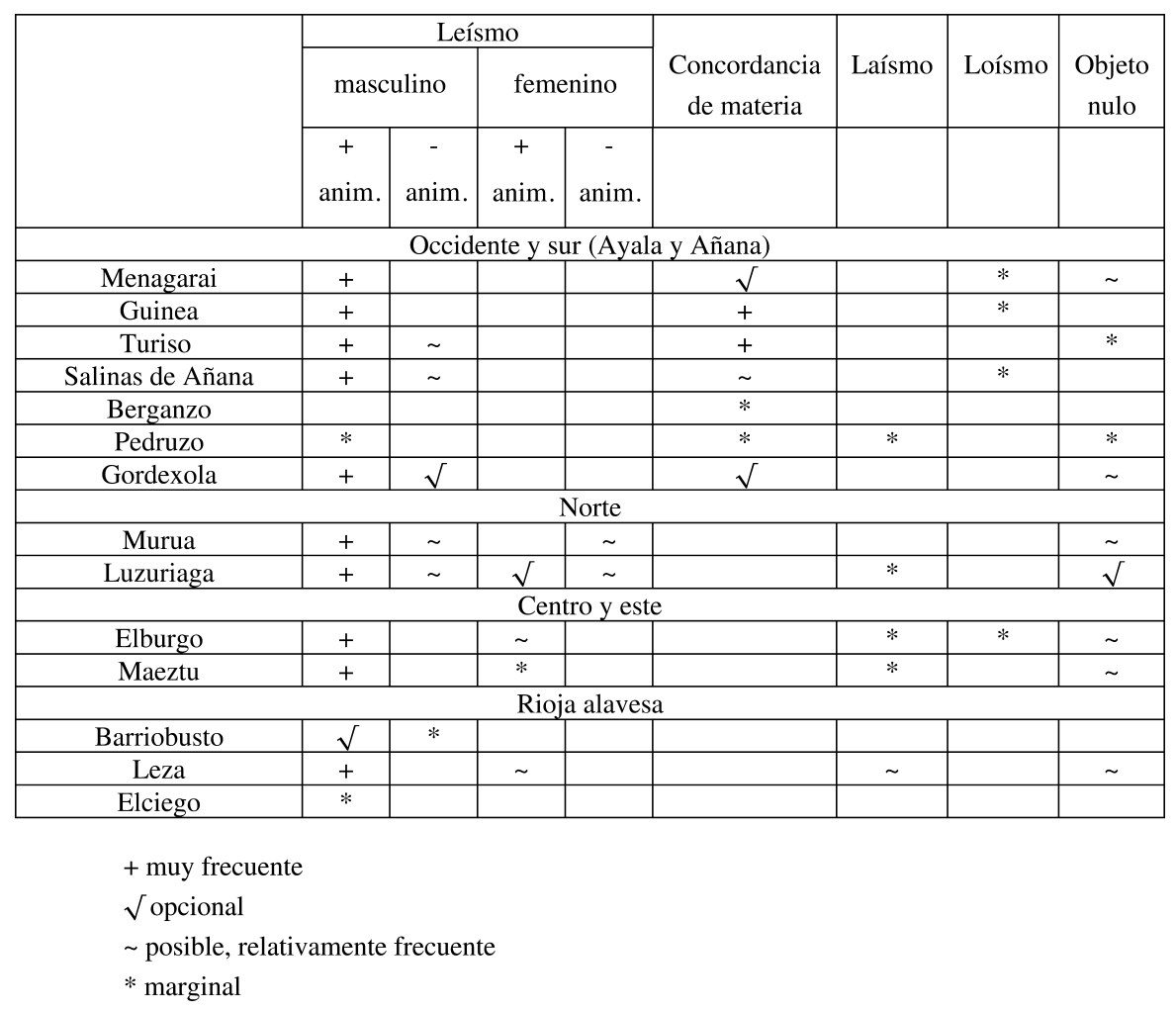

TABLA 3.-Características de los usos pronominales de los puntos alaveses del COSER.

2.2.6. Distribución geográfica de los sistemas pronominales en Álava. Si se trasladan los datos expuestos al mapa de Álava, representado en Mapa 3, se comprueba la presencia de distintos sistemas pronominales, que se prolongan en un continuo con respecto a los sistemas descritos en otras zonas limítrofes. De esta manera, en el occidente de Álava y de norte a sur, desde Menagarai hasta Berganzo, con penetración en Pedruzo, en el Condado de Treviño (véase Mapa 3, los lugares marcados con un triángulo), se localiza el sistema pronominal de transición nororiental, extendido desde la comarca vizcaína de Las Encartaciones hasta la esquina nororiental de Burgos. De acuerdo con los datos recogidos, este sistema distingue los sustantivos continuos, tanto masculinos como femeninos, que se pronominalizan con $l o$, mientras que los sustantivos discontinuos se refieren con le/s cuando son masculinos. En el sur de Álava, por su parte, en la Rioja alavesa (véase Mapa 3, localidades marcadas con un cuadrado), dos de los tres puntos analizados (Barriobusto y Elciego) revelan un sistema distinto al del occidente: fundamentalmente etimológico, a excepción 
de cierto leísmo masculino animado $-\mathrm{y}$ ocasionalmente inanimado-, y sin rastro de concordancias de materia ni de objetos nulos. Tal sistema probablemente sea continuación del atestiguado en gran parte de La Rioja, salvo en su esquina más nororiental. El sistema de Leza, el tercero de los puntos analizados en esta zona, extiende el leísmo a masculinos y a femeninos, muestra ejemplos de omisión de objetos directos inanimados definidos, así como casos de laísmo. Como ya dijimos, esta excepcionalidad puede ser debida al sesgo que proporcionan las circunstancias de los informantes utilizados en este lugar.

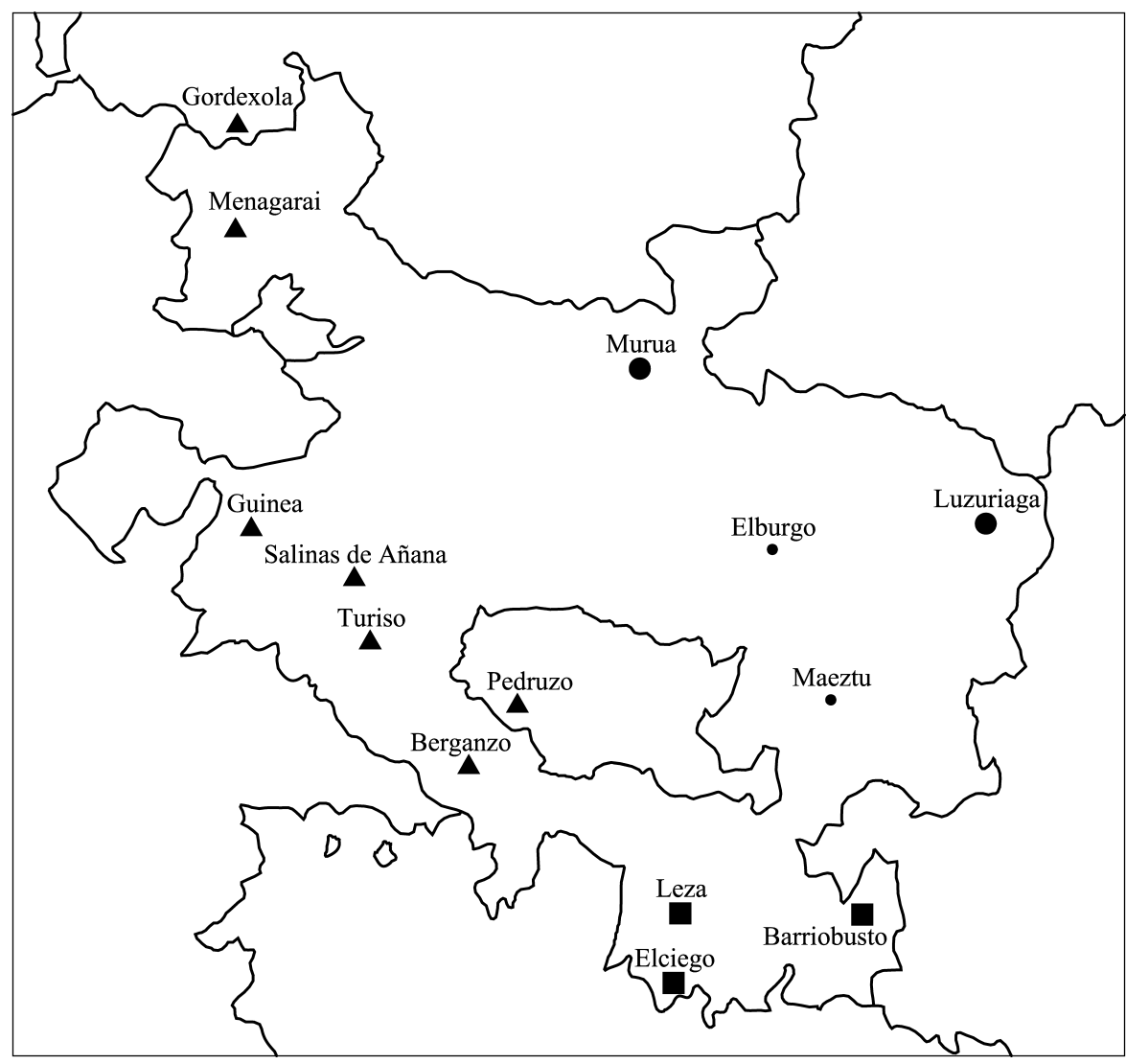

MAPA 3.-Sistemas pronominales en Álava a partir del COSER.

Por otro lado, en el norte de la provincia y hacia el este, desde Murua a Luzuriaga (véase Mapa 3, marcadas con un círculo), se descubre un sistema coincidente en sus características fundamentales con el sistema pronominal presente en el español hablado en Guipúzcoa y la zona vascoparlante de Vizcaya y 
Navarra. Esto es, con preferencia por los usos leístas, fundamentalmente con entidades animadas masculinas y, a veces, femeninas, así como con tendencia a la omisión de objetos referidos a entidades inanimadas, definidas y específicas. Estos usos pronominales, continuación del sistema vasco, se extienden también por el centro-este de Álava, por los territorios de la Llanada y la Montaña alavesa (véase Mapa 3, puntos señalados con círculo pequeño), donde es posible atestiguar leísmo animado masculino —y femenino, a veces_-, así como la elisión de objetos directos inanimados. No obstante, ambos fenómenos resultan menos frecuentes que en el norte.

\section{El español de Álava y los ROMANCES del País VASCO}

El conjunto de los datos que acabamos de ofrecer y su descripción podrían ser reflejo de distintas variedades de romance en el País Vasco, así como testimonio de la presencia de las mismas en Álava de manera aun hoy suficientemente consistente. Estas variedades de romance diferirían por su desarrollo histórico y sociolingüístico, a la manera propuesta para Navarra por Saralegui (2003, 2003-2004, 2006, 2011) y Saralegui y Lesaca (2002). En efecto, estos trabajos proporcionan datos fonéticos, morfológicos y léxicos que permiten distinguir dos tipos de romance en el área navarra, uno patrimonial y otro importado. Así, en la Navarra media y meridional se distingue un romance autóctono o patrimonial, que se integró en el complejo dialectal castellano a finales de la Edad Media y que en la actualidad se reconoce como un español con regionalismos. En contraste con lo precedente, la Navarra septentrional, presumiblemente vascohablante, adoptó el castellano (entendido como variedad de Castilla la Vieja, es decir, en su sentido estricto medieval), por lo que este castellano fue un romance importado y se configuró como modalidad próxima al estándar.

Como ejemplos ilustrativos de lo anterior, cabe citar la conservación del léxico dialectal en la Navarra media y meridional, frente a la norteña, con preferencia por un vocabulario tipológicamente castellano (Saralegui y Lesaca, 2002: 1765-1766). Con respecto a la morfología, el norte prefiere las formas normalizadas conmigo y contigo, en tanto que las zonas media y sur optan por el uso regional con mí, con ti (y con tú, pa(ra) tú) (Saralegui, 2003-2004). En la misma línea, en ciertas formas del presente de indicativo (medimos, medís), la Navarra noroccidental sigue la morfología castellana estandarizada, mientras que el centro y sur, junto a las formas citadas, conserva vacilaciones de vocal temática y de desinencia (midemos, midimos, y midís, midéis, medéis) registradas en otras áreas dialectales, como la riojana y la aragonesa, y en los niveles menos instruidos (Saralegui, 2003). Una distribución geográfica parecida se registra para algunos hechos fonéticos, como la tendencia a la desaparición de - 
y- intervocálica por ejemplo en cayendo (caendo, caíndo), fenómeno de adscripción dialectal más amplia pero desconocido en la Navarra noroccidental (Saralegui, 2011).

Un análisis similar al propuesto para Navarra es el que en este apartado expondremos para los territorios del País Vasco, con los debidos matices históricos, geográficos y sociolectales (\$3.1). Asimismo, demostraremos que los usos pronominales descritos en este trabajo permiten sostener las distinciones que proponemos (\$3.2), si bien son necesarios más datos lingüísticos que corroboren las tesis planteadas aquí.

\subsection{Romance importado y romance patrimonial en el País Vasco}

Efectivamente, como hemos venido defendiendo en trabajos recientes (Camus Bergareche, 2011b; Camus y Gómez, 2012) a partir del análisis propuesto para Navarra (Saralegui, 2003, 2003-2004, 2006, 2011; Saralegui y Lesaca, 2002), el español que se habla hoy como lengua nativa en el País Vasco puede describirse como correspondiente históricamente a distintas variedades de romance, diferenciadas por su desarrollo histórico y sociolingüístico. En síntesis, se trata básicamente de dos tipos de romance, uno importado y otro patrimonial. El primero, el romance importado, es la variedad castellana que provoca el importante retroceso geográfico y social de la lengua vasca desde el siglo XVI; el segundo, el llamado romance patrimonial, es la variedad románica surgida directamente del latín hablado en los bordes occidental y meridional del territorio vasco. Veámoslo en detalle.

La modalidad lingüística nativa más extendida por el País Vasco es la que resulta del proceso de castellanización que se inició a finales de la Edad Media y que se ha venido desarrollando con diferente intensidad hasta nuestros días. Esta variedad es la que llamamos romance importado, que en el caso del País Vasco corresponde a una variedad de español que suele denominarse castellano del País Vasco ${ }^{11}$. Este castellano del País Vasco se extiende por aquellos territorios en los que la lengua vasca fue desplazada y en gran medida sustituida por el español. Desde el comienzo de la Edad Moderna, los núcleos urbanos como Bilbao, Vitoria, (y en Navarra, Estella o Tafalla), próximos a la frontera entre la lengua vasca y el español, fueron progresivamente más permeables a la

${ }^{11}$ Para esta variedad de español suele preferirse la denominación de castellano del País Vasco antes que la de español del País Vasco porque, en primer lugar, es el nombre que sus usuarios y hablantes utilizan de modo muy mayoritario y, por otro, porque es la que permite establecer con claridad la indudable vinculación histórica y la coincidencia de rasgos de esta variedad respecto al español del norte peninsular, el de Castilla la Vieja. Véanse, al respecto, las consideraciones de Echenique (2013b: 183). 
castellanización (Camus Bergareche, 2011b: 67). De resultas de este proceso, para comienzos del siglo XIX en las Encartaciones orientales, Valle de Ayala, comarcas de Vitoria y su llanada, Valles y Montaña alavesa (y en Navarra, la zona media) encontramos un romance importado o de sustitución ${ }^{12}$, estrechamente relacionado con la lengua vasca, que funcionó como sustrato, y que nutrió a este romance importado de voces como chalo 'aplauso', choriburu 'alocado' o petacho 'remiendo' (Camus Bergareche, 2011b y la bibliografía específica citada). En síntesis, son los territorios que en el Mapa 4 aparecen en distintos tonos de gris formando una corona que rodea por el oeste y el sur el área vascófona contemporánea ${ }^{13}$.

Este romance importado se ha convertido también en la lengua materna de una gran parte de la población vasca actual en el interior de la zona vascófona, ya que desde el siglo XIX estos territorios vivieron un importante proceso de castellanización, intensificado por el aumento de la escolarización y la consiguiente alfabetización. Además, por vez primera, la castellanización no se limitó a las zonas de frontera lingüística, sino que afectó al interior del dominio vascohablante. El desplazamiento de la lengua vasca siguió produciéndose, por tanto, en términos geográficos, pero comenzó a ocurrir a nivel social entre las capas altas y medias de las ciudades de la Vasconia interior como San Sebastián (Camus y Gómez, 2010). Con todo, en estos territorios el castellano del País Vasco convivió (y convive) con el euskera, a diferencia de lo que ocurrió en los territorios señalados anteriormente, donde la adopción del romance importado supuso prácticamente la desaparición de la lengua vasca como lengua materna.

La segunda modalidad lingüística romance presente en el País Vasco presenta, sin embargo, una historia sensiblemente distinta. Se trata de una variedad desarrollada a partir del latín hablado en áreas de romanización antigua y, por tanto, puede ser considerada justamente como una modalidad autóctona de romance o romance patrimonial ${ }^{14}$. Es lo que se encuentra ya desde la Alta Edad Media en las áreas que en el Mapa 4 más arriba aparecen en blanco: el extremo

12 A este respecto conviene subrayar que esta zona es en buena medida un área donde el bilingüismo vascuence / romance debió ser corriente desde bien temprano, como prueban la toponimia y multitud de testimonios documentales (González Ollé, 2004; Echevarría Isusquiza, 2012). La presencia habitual y antigua de las dos lenguas es la que, sin duda, se dio en los grandes núcleos urbanos, especialmente en Pamplona o Vitoria, lo que explica que el desplazamiento prácticamente completo del euskera ocurriera en estas ciudades bastante antes que en su entorno rural.

13 Del área en blanco del Mapa 4 nos ocuparemos más adelante.

${ }^{14}$ Algunos datos sobre las características del romance de Vizcaya, Álava y Navarra se conocen a partir de los trabajos ya clásicos de investigadores como Echevarría Isusquiza, Isasi, Ciérbide, Líbano y, sobre todo, González Ollé. Véase la síntesis y bibliografía recogida en Gómez y Ramírez (2007). 


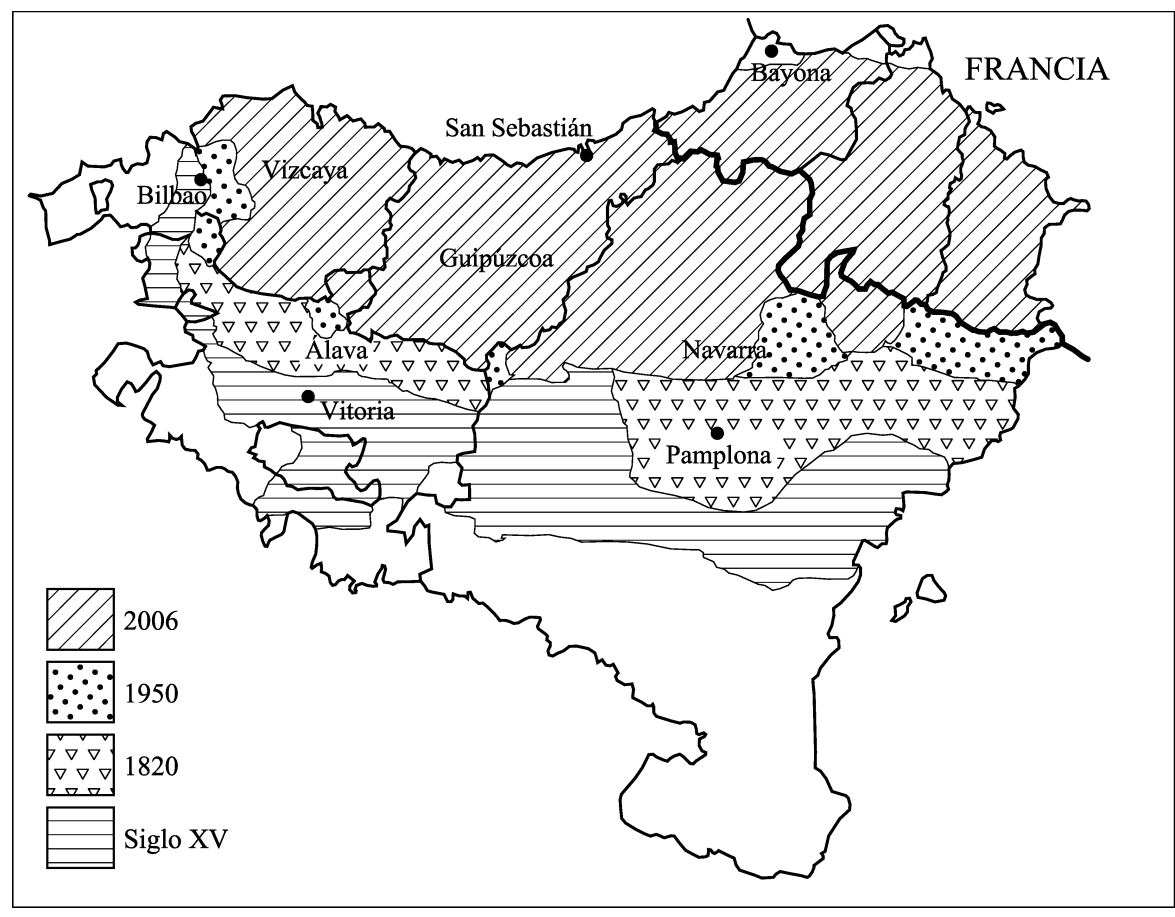

MAPA 4.-El retroceso del euskera (elaboración propia a partir de Arejita, Manterola y Oar-Arteta, 2007).

occidental y centro de las Encartaciones en Vizcaya, el occidente del valle de Ayala o Añana y, por otro lado, la Rioja alavesa (y el sur de Navarra).

Son territorios en los que el romance es continuación natural del latín de época romana, al igual que ocurre con los territorios limítrofes por el oeste, sur y este, cuyo rastro ha perdurado en la toponimia, con absoluta predominancia de elementos románicos sobre los vascos (para la zona encartada vizcaína, vid. Echevarría Isusquiza, 1998). Como mostraremos más adelante, ocurre, además, que este romance patrimonial presenta en el País Vasco, y por añadidura en Álava, dos bases bien diferenciadas, una castellana vinculada a las hablas cántabras y burgalesas y otra navarro-riojana (Camus Bergareche, 2011b). A este respecto, resultan ilustrativos las coincidencias y el grado de continuidad del romance patrimonial respecto a las hablas románicas vecinas, esto es, las variedades castellanas de Cantabria, Burgos y las hablas riojanas, navarras o aragonesas. Como ejemplo, cabe citar la pronunciación rehilada o asibilada de la [r] en el habla de la Rioja Alavesa y la Ribera navarra, en coincidencia con las hablas del otro lado del Ebro en la Rioja Baja (Echenique, 1984: 69). 


\subsection{La diversidad actual del castellano en Álava: una hipótesis}

Pues bien, la distribución de los usos pronominales que hemos mostrado para el español que se habla hoy en Álava (\$2.2) puede constituir un argumento en favor de las consideraciones que acabamos de hacer sobre los diferentes tipos de español en el País Vasco (\$3.1). Esta conclusión, en realidad, se encuentra en consonancia con ideas ya apuntadas en trabajos anteriores, señaladamente el de Echevarría Isusquiza (2012: 112-113):

Proporcionar contenido a la excepción vasca requiere definir los espacios de diversidad interna, en precisa coherencia con el bien asumido planteamiento de Penny (2004). De la propia concepción de contínuum se desprende que el gradiente de isoglosas que lleva de lo típicamente riojano hasta lo típicamente montañés, dentro del área castellana, se produce a través del espacio vasco, entendido el adjetivo en su dimensión geopolítica. Y que hablar de "castellano del País Vasco" solo es posible a condición de aceptar su pluralidad constitutiva, la cual empieza por asumir la desigual participación de la lengua vasca en la historia lingüística del País Vasco y reconocer espacios románicos primitivos, desarrollados en un territorio posiblemente ya no vasco tampoco en el momento de su latinización.

No obstante, es una idea que también está presente en descripciones más o menos parciales y datos indirectos sobre el español de Álava de trabajos más antiguos, como los de Baráibar (1903), Apraiz (1953), López de Guereñu (1998 [1958]) o Knörr (1998).

3.2.1. Romance patrimonial en Álava: romance castellano y romance navarro-riojano. El análisis de los sistemas pronominales visto en $\S 2.2 .1$ y $\S 2.2 .4$ permite reconocer en Álava un espacio de romance patrimonial que constituye la continuación de las hablas del nordeste burgalés y de La Rioja. En él situaríamos, en primer lugar, una zona en el occidente —cuadrillas de Ayala, Añana y oeste de Treviño - con un español de tipo dialectal claramente castellano, con leísmo y concordancia de materia, con evidentes correspondencias, por lo tanto, con el oriente cántabro y occidente vizcaíno. Se trata del sistema de transición nororiental con leísmo para referentes masculinos discontinuos (animados e inanimados) y el uso de lo para entidades continuas (en masculino y femenino). Son, como se muestra en el Mapa 5, áreas donde en la Alta Edad Media debió de formarse un romance castellano que llegaba a penetrar en los territorios vascófonos contiguos, donde el bilingüismo se convirtió en la situación dominante a lo largo de los siglos siguientes.

Un segundo tipo de español históricamente vinculado con el romance patrimonial sería el que hoy se conserva en la Rioja alavesa y sur de Navarra. A diferencia del sistema castellano descrito para la zona alavesa occidental, el sis- 
tema pronominal que se encuentra en este lugar ya no tiene concordancia de materia y solo presenta casos de leísmo con animados masculinos, con lo que coincide en sus rasgos con el sistema distinguidor general en el sur de Navarra, La Rioja y Aragón. Se trataría, por tanto, de una variedad de español con elementos locales propiamente riojanos que son resultado de la disgregación progresiva del romance navarro-riojano propio de esta zona en la Edad Media (vid. Mapa 5).

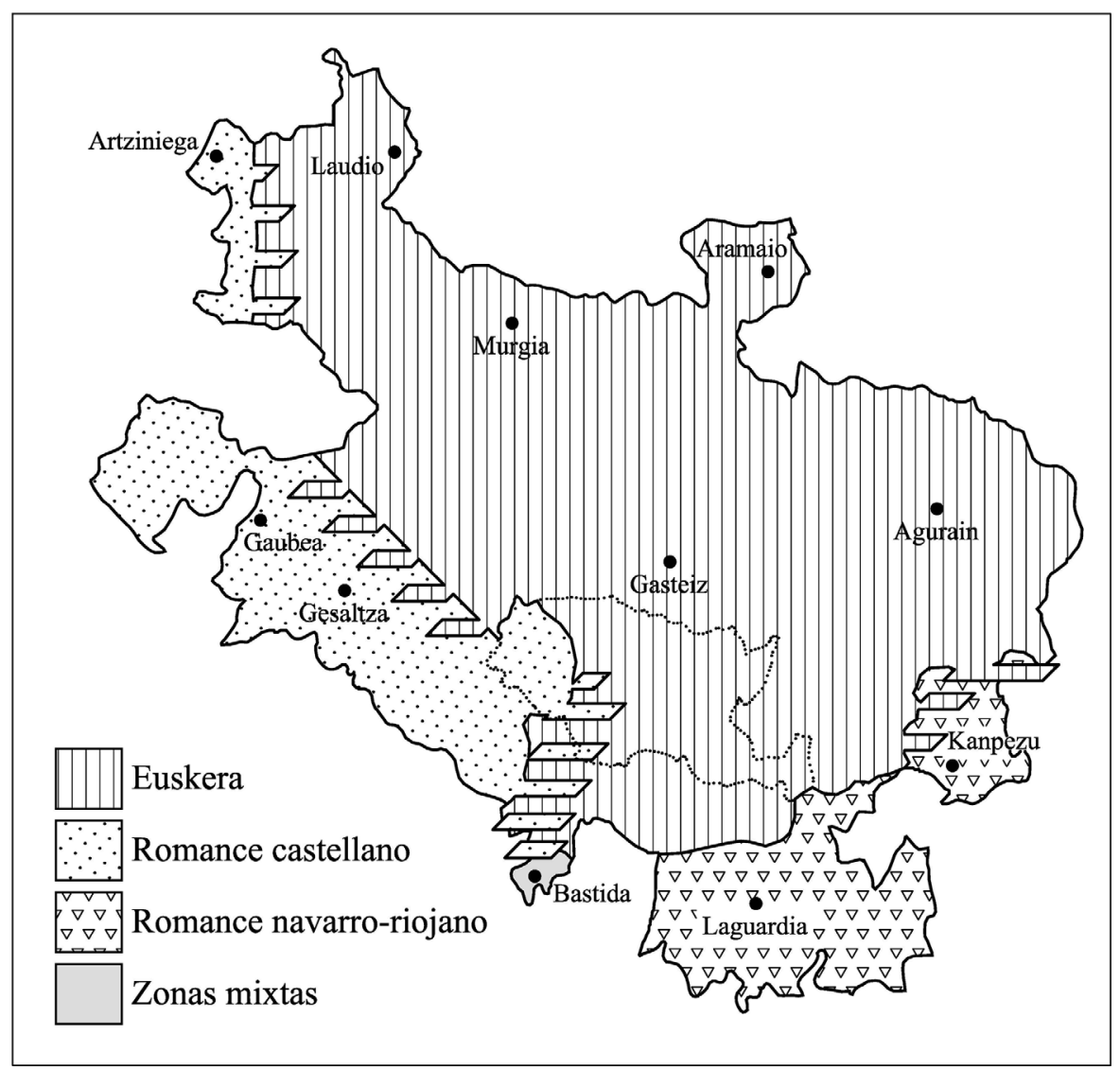

MAPA 5.-Zonas lingüísticas en Álava en la Alta Edad Media (elaboración propia a partir de Arejita, Manterola y Oar-Arteta, 2007: 44; Martínez y González, 2012).

3.2.2. Romance importado en Álava. Por el contrario, el dominio señalado con rayado vertical en el Mapa 5 está constituido por territorios antiguamente vascófonos en los que el euskera fue progresivamente desplazado por una variedad de castellano en que, sin duda, era posible encontrar elementos propios 
del romance patrimonial contiguo, pero también, y sobre todo, elementos explicables desde el contacto intenso y secular con el euskera. Son, por tanto, áreas de romance importado o, en definitiva, castellano del País Vasco más o menos cercano al que se encuentra en la mayoría de Vizcaya y Guipúzcoa (y norte de Navarra). Es lo que de manera interesante parece mostrar una vez más el análisis de los sistemas pronominales de $§ 2.2 .2$ y $§ 2.2 .3$. Encontramos en el borde norte del territorio alavés hablas como las de Murua o Luzuriaga, donde los rasgos del sistema pronominal vasco, con leísmo generalizado (sobre todo, con animados masculinos y femeninos, pero también con inanimados) y omisión de pronombres para referentes inanimados, se documentan abundantemente. Nótese que los pueblos citados se encuentran en la franja más septentrional de Álava, el territorio en que el euskera seguía todavía vivo a mediados del siglo XIX, como muestra el Mapa 6 a continuación, que reproduce parcialmente el célebre mapa de Odón de Apraiz (1953). Efectivamente, en él se indican como límite sur del vasco en 1850 pueblos como Letona, del que Murua queda a tan solo una decena de kilómetros al norte, o Araya, del que Luzuriaga dista unos pocos kilómetros hacia el este.

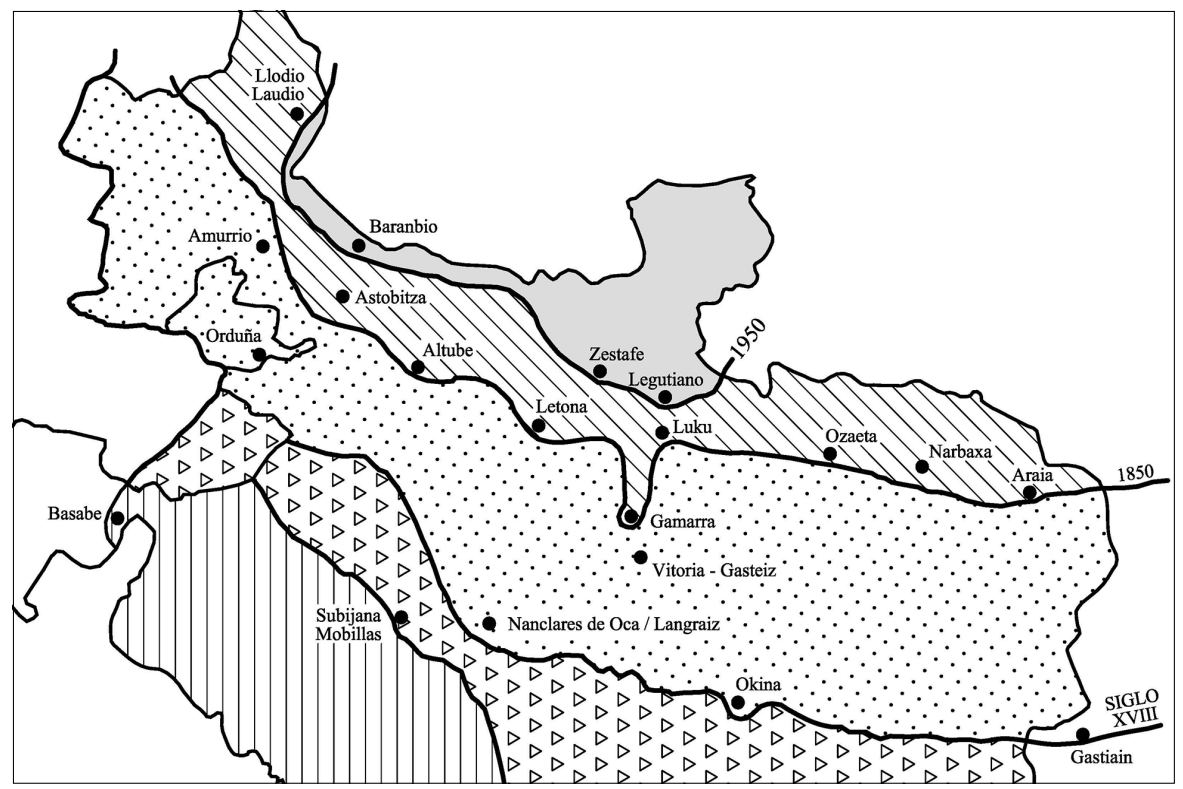

MAPA 6.--Retroceso del euskera en el centro y norte de Álava (adaptado de Apraiz, 1953).

Por el contrario, estos mismos rasgos (leísmo y omisión de objetos) se documentan, como vimos, con una frecuencia menor con respecto a la zona anteriormente descrita en las localidades del centro de la Llanada (Elburgo) o la 
Montaña alavesa (Maeztu). No puede ser casual el hecho de que se trate de localidades situadas en la franja ancha marcada con pequeños puntos que en el Mapa 6 discurre por todo el centro de Álava e incluye, entre otras localidades, a la capital, Vitoria. Es, como se indica en el propio mapa, el área donde la lengua vasca es sustituida definitivamente por el romance importado a lo largo del siglo XVIII. Se trata, por tanto, de un tipo de castellano del País Vasco que sirve de transición, por un lado, al español de reminiscencias riojanas de la Rioja alavesa al sur y, por otro, a las hablas de tipo castellano burgalés de Ayala, Añana y Treviño por el oeste.

De acuerdo con lo descrito, quedaría de manifiesto la complejidad lingüística alavesa que, como hemos visto, permite reconocer con claridad territorios cuya lengua presenta una base de romance patrimonial, bien castellano, bien navarroriojano, y territorios donde el español ha ido desplazando a la lengua vasca a lo largo de los últimos quinientos años, con el resultado de variedades de castellano del País Vasco más cercano al que se encuentra en Vizcaya o Guipúzcoa. Parece necesario, además, incluir en esta caracterización la existencia en un periodo anterior de áreas más o menos extensas, en las que probablemente hay que incluir la capital, Vitoria-Gasteiz, donde lo habitual era la convivencia de euskera y romance. Este reparto lingüístico primitivo de límites difusos es lo que ayuda a explicar - sin perjuicio del reconocimiento de la evidente variedad dialectal— la existencia actual de un continuum relativo en que los rasgos propios de cada modalidad van, según refleja la Tabla 3, progresivamente diluyéndose y mezclándose con los de las demás a medida que nos movemos en una dirección u otra y consideramos cada una de las distintas localidades encuestadas para el COSER.

\section{BIBLIOGRAFÍA}

Apraiz, Odón de (1953): El vascuence en Álava (su retroceso desde el siglo XIII a 1950), Vitoria, mapa. Arejita, Adolfo, Ander Manterola y Segundo Oar-Arteta (2007): Euskararen geografia historikoa, Vitoria-Gasteiz, Eusko Jaurlaritza.

Baráibar, Federico (1903): Vocabulario de palabras usadas en Álava y no incluidas en el Diccionario de la RAE ó que estan en otras acepciones ó como anticuadas, Madrid, Jaime Ratés.

Camus Bergareche, Bruno (2011a): "Restricciones aspectuales y la perífrasis <soler + inf.>”, en Juan Cuartero Otal, Luis García Fernández, Carsten Sinner (eds.), Estudios sobre perífrasis y aspecto, München, Peniope, pp. 120-138.

Camus Bergareche, Bruno (2011b): "El castellano de San Sebastián: desarrollo y caracterización”, Oihenart, XXVI, pp. 59-101.

Camus Bergareche, Bruno y Sara Gómez Seibane (2010): "Historical Sociolinguistics in $19^{\text {th }}$ century San Sebastián: Basque and Spanish in competition”, Ianua. Revista Philologica Romanica, X, pp. 223-239.

Camus Bergareche, Bruno y Sara Gómez Seibane (2012): “Introducción: El castellano del País Vasco", en Bruno Camus Bergareche y Sara Gómez Seibane (eds.), El castellano del País Vasco, Bilbao, Univ. del País Vasco/Euskal Herriko Unibertsitatea, pp. 1-17. 
Echaide, Ana M.. (1968): Castellano y vasco en el habla de Orio. Estudio sobre la lengua tradicional e importada, Pamplona, Institución Príncipe de Viana.

Echenique, M. ${ }^{a}$ Teresa (1984): Historia lingüística vasco-románica, San Sebastián, Caja de Ahorros Provincial.

Echenique, M. ${ }^{a}$ Teresa (1986): "El romance en territorio euskaldun", en Ricardo Ciérbide (dir.), Lengua y literatura románica en torno al Pirineo, Bilbao, Univ. del País Vasco/Euskal Herriko Unibertsitatea, pp. 153-169.

Echenique, M. ${ }^{a}$ Teresa (1996): "La lengua castellana hablada en el País Vasco: A propósito de los clíticos de tercera persona", en Antonio Briz et al. (eds.), Pragmática y gramática del español hablado, Valencia, Pórtico, pp. 65-74.

Echenique, M. ${ }^{a}$ Teresa (1997): Estudios lingüísticos vasco-románicos, Madrid, Istmo.

Echenique, M. ${ }^{a}$ Teresa (2013a): "Dialectos románicos y dialectos vascos en contacto en la protohistoria románica", Aemilianense, III, pp. 23-45.

Echenique, Ma Teresa (2013b): "Bruno Camus Bergareche/Sara Gómez Seibane (eds.) El castellano del País Vasco, Bilbao, Univ. del País Vasco (Anejos de Filología Vasca "Julio de Urquijo”, LXX), 2012, 288 págs. ISBN 9788498607673", Revista Internacional de Lingüística Iberoamericana, 11/2, pp. 182-187.

Echevarría Isusquiza, Isabel (1998): Estudio lingüístico de la toponimia de Carranza (Vizcaya), Bilbao, Univ. del País Vasco/Euskal Herriko Unibertsitatea.

Echevarría Isusquiza, Isabel (2012): "Del castellano y la toponimia del País Vasco", en Bruno Camus Bergareche y Sara Gómez Seibane (eds.), El castellano del País Vasco, Bilbao, Univ. del País Vasco / Euskal Herriko Unibertsitatea, pp. 87-116.

Elordieta, Gorka (2003): "The Spanish Intonation of Speakers of a Basque Pitch Accent Dialect", Catalan Journal of Linguistics, II, pp. 67-95.

Etxebarria, Maitena (1986): "El castellano actual en el País Vasco: estudio de interferencias", en Manuel Alvar, Maitena Etxebarria, Constantino García, Francisco Marsá (eds.), El castellano actual en las comunidades bilingües de España, Salamanca, Junta de Castilla y León, pp. 65-91.

Fernández-Ordóñez, Inés (1994): "Isoglosas internas del castellano: el sistema referencial del pronombre átono de tercera persona", Revista de Filología Española, LXXIV, pp. 71-125.

Fernández-Ordóñez, Inés (1999): "Leísmo, laísmo y loísmo", en Ignacio Bosque y Violeta Demonte (dirs.), Gramática Descriptiva de la Lengua Española, Madrid, Espasa Calpe, I, pp. 1317-1397.

Fernández-Ordóñez, Inés (2001): "Hacia una dialectología histórica: reflexiones sobre la historia del leísmo, el laísmo y el loísmo", Boletín de la Real Academia Española, LXXXI, pp. 389464.

Fernández-Ordóñez, Inés (dir.) (2005-): Corpus oral y sonoro del español rural (COSER), Univ. Autónoma de Madrid, <uam.es/COSER/>.

Fernández Ulloa, Teresa (2001): "Perífrasis verbales en el castellano de Bermeo (Vizcaya)", Re vista Española de Lingüística, XXI, pp. 1-34.

García González, Francisco (1989): "El neutro de materia”, Homenaje a Alonso Zamora Vicente, Madrid, Cátedra, vol. II, pp. 91-105.

García González, Francisco (1999): "Geografía del neutro de materia", Corona spicea in memoriam Cristóbal Rodríguez Alonso, Oviedo, Univ. de Oviedo, pp. 527-542.

Gómez Seibane, Sara (2012a): Los pronombres átonos (le, la, lo) en el español, Madrid, Arco/ Libros.

Gómez Seibane, Sara (2012b): "La omisión y duplicación de objetos en el castellano del País Vasco", en Bruno Camus Bergareche y Sara Gómez Seibane (eds.), El castellano del País Vasco, Bilbao, Univ. del País Vasco/Euskal Herriko Unibertsitatea, pp. 193-214.

Gómez Seibane, Sara y José L. Ramírez Luengo (2007): "La historia del castellano en el País Vasco: recuento bibliográfico, trabajos desarrollados, perspectivas de futuro", Revista Internacional de Lingüística Iberoamericana, 10, pp. 221-240. 
González Ollé, Fernando (1991): "La posición de Navarra en el dominio lingüístico navarro-aragonés", en José María Enguita (ed.), Actas del Congreso de lingüistas aragoneses, Zaragoza, pp. 55-68.

González Ollé, Fernando (2004): "Navarra, Romania emersa y ¿Romania submersa?", Aemilianense, I, pp. 225-270.

Gorrochategui, Joaquín (1999): "La romanización del País Vasco: Aspectos lingüísticos", Antiqua, VI Jornadas sobre la Antigüedad, San Sebastián, Diputación Foral de Guipúzcoa, pp. $10-23$.

Iribar, Alexander y Carmen Isasi (2008): "El seseo vasco: nuevos datos para una vieja cuestión", en Sara Gómez Seibane y José L. Ramírez Luengo (eds.), Oihenart, 23: Segundas jornadas de Lingüística Vasco-Románica: Nuevos estudios, San Sebastián, Eusko Ikaskuntza, pp. 241258.

Knörr, Henrike (1998): Lo que hay que saber sobre la lengua vasca en Álava/Arabako euskarari buruz jakin behar dena, Vitoria-Gasteiz, Fundación Caja Vital Kutxa.

Korkostegi, M. ${ }^{a}$ José (1992): Pío Baroja y la gramática. Estudio específico del leísmo, laísmo y loísmo y la duplicación de clíticos, San Sebastián, Universidad de Deusto.

Landa, Alazne (1993): "Los objetos nulos determinados del español del País Vasco", Lingüística, V, pp. 131-146.

Landa, Alazne y Jon Franco (1992): "Objetos nulos en el castellano del País Vasco: dos estatus para dos interpretaciones", Anuario del Seminario de Filología Vasca Julio de Urquijo, XXVI, pp. 777-792.

López de Guereñu, Gerardo (1998 [1958]): Voces alavesas, 2. ${ }^{a}$ edición a cargo de Henrike Knörr, Bilbao, Euskaltzaindia.

Martínez de Madina, Elena y Roberto González de Viñaspre (2012): "Observaciones para una delimitación de la lengua vasca en Álava", Fontes Linguae Vasconum, CXIV, pp. 135-143.

Oñederra, Lourdes (2004): "El español en contacto con otras lenguas: español-vasco", en Rafael Cano (coord.): Historia de la lengua española, Barcelona, Ariel, pp. 1103-1115.

Ramírez Luengo, José L. (2012): "Diacronía y sincronía del uso del condicional por el pasado de subjuntivo en el castellano del País Vasco", en Bruno Camus Bergareche y Sara Gómez Seibane (eds.), El castellano del País Vasco, Bilbao, Universidad del País Vasco / Euskal Herriko Unibertsitatea, pp. 235-253.

Santiago, Ramón (1977): "Notas sobre la lengua y escribanos en documentos medievales alaveses", Boletín del Instituto Sancho el Sabio, XXI, pp. 235-257.

Saralegui, Carmen (2003): "Morfología verbal y cronología y tipos de castellanización en Navarra", en Concepción Alonso del Real et al. (eds.), Urbs Aeterna. Actas y colaboraciones del Coloquio Internacional Roma, entre la literatura y la historia. Homenaje a Carmen Castillo, Pamplona EUNSA, pp. 921-934.

Saralegui, Carmen (2003-2004): "Discrepancias mofológicas navarras y tipos de romance", en Rosa M. ${ }^{a}$ Castañer y José M. ${ }^{a}$ Enguita (eds.), Archivo de Filología Aragonesa. In memoriam Manuel Alvar, LIX-LX, pp. 1669-1682.

Saralegui, Carmen (2006): "Notas para la identificación de dos tipos de romance en Navarra", en Carmen Isasi y Sara Gómez Seibane (eds.), Oihenart, 21: Lingüística Vasco-Románica, San Sebastián, Eusko-Ikaskuntza, pp. 453-465.

Saralegui, Carmen (2011): "Sobre geografía linguiística de Navarra: de nuevo el norte y el sur", Archivo de Filología Aragonesa, LXVII, pp. 75-112.

Saralegui, Carmen y Mónica Lesaca (2002): "Romance patrimonial y romance importado en Navarra: una muestra", en M. ${ }^{a}$ Teresa Echenique y Juan P. Sánchez Méndez (coords.), Actas del $V$ Congreso Internacional de Historia de la Lengua Española, Madrid, Gredos, II, pp. 17651779 .

Torres Garoña, Gema M. (1993): "Interferencias léxicas vasco-románicas en el castellano de San Sebastián", Anuario del Seminario de Filología Vasca Julio de Urquijo, 27/2, pp. 449-538. 
Túrrez, Itziar (1988): "Características fonéticas del español en el País Vasco", Letras de Deusto, XL, pp. 65-79.

Urrutia, Hernán (1988): "El español en el País Vasco: peculiaridades morfosintácticas", Letras de Deusto, XL, pp. 33-43.

Urrutia, Hernán (2006): "El bilingüismo en la CAV (Comunidad Autónoma Vasca): aspectos lingüísticos y educativos", en Carmen Isasi Martínez y Sara Gómez Seibane (eds.), Lingüística Vasco-Románica / Euskal-Erromantze Linguistika, San Sebastián, Eusko-Ikaskuntza, pp. 481-520.

Zárate, Mikel (1976): Influencias del vascuence en la lengua castellana a través de un estudio del elemento vasco en el habla coloquial de Chorierri (Gran Bilbao), Bilbao, Gran Enciclopedia Vasca.

Fecha de recepción: 6 de febrero de 2014

Fecha de aceptación: 24 de noviembre de 2014 